\title{
PENDIDIKAN KESEHATAN PERSIAPAN MENYUSUI PADA WANITA USIA SUBUR
}

\author{
Health Education On Breastfeeding Preparation \\ For Childbearing-Age Women
}

\author{
Sitti Khadijah ${ }^{1}$, Dheska Arthyka Palifiana ${ }^{2}$, Zahrah Zakiyah ${ }^{3}$ \\ Fakultas Ilmu Kesehatan, Universitas Respati Yogyakarta \\ Jl. Raya Tajem KM 1,5 Maguwoharjo, Depok, Sleman, Yogyakarta \\ (cha_midwife19@yahoo.com)
}

\begin{abstract}
ABSTRAK
Latar Belakang : Memberikan ASI untuk bayi menjadi tantangan untuk ibu walaupun menyusui merupakan suatu hal yang alamiah. Keberhasilan dalam menyusui tetap memerlukan pengetahuan tentang ASI dan tatalaksananya. Sehingga pendidikan kesehatan mengenai persiapan menyusui sangat penting untuk memulai proses menyusui.

Tujuan : Penelitian ini bertujuan untuk mengetahui pengaruh pendidikan kesehatan mengenai persiapan menyusui terhadap pengetahuan wanita usia subur.

Metode : Desain yang digunakan adalah Quasi Eksperiment dengan menggunakan rancangan pre post dan menggunakan jenis rancangan one group design. Sampel penelitian yang digunakan dalam penelitian ini sebanyak 21 responden. Pendidikan kesehatan dilakukan secara online via WhatsApp. Analisis data menggunakan uji Paired $T$ Test yang sebelumnya telah dilakukan uji normalitas.

Hasil : Mayoritas responden berada pada tingkat pendidikan tinggi (95,2\%), status bekerja $(57,1 \%)$ dan dalam keadaan hamil $(66,7 \%)$. Pada saat pre test jumlah responden yang berpengetahuan baik sebanyak 5 orang $(23,81 \%)$ dan pada saat post test jumlah responden yang berpengetahuan baik sebanyak 16 orang $(76,2 \%)$. Nilai signifikansi (2-tailed) adalah 0,004 ( $<<0,05)$.
\end{abstract}

Simpulan : Pendidikan kesehatan online melalui aplikasi whatsapp dapat meningkatkan pengetahuan tentang persiapan menyusui.

Kata Kunci : Pendidikan Kesehatan, Persiapan Menyusui, Wanita Usia Subur

\begin{abstract}
Background: Breastfeeding for babies is a challenge for mothers even though breastfeeding is a natural activity. The success of breastfeeding still requires knowledge about breast milk and how to do it properly. Therefore, health education on breastfeeding preparation is highly important to start the breastfeeding process.

Purpose: This study aims to find out the effect of health education regarding breastfeeding preparation on the knowledge of childbearing-agewomen.
\end{abstract}


Method: The employed design wasquasi-experimental design using pre-post design and one-group design. The number of samples in this study was 21 respondents. Health education wasconducted online via WhatsApp. Furthermore, data then analyzed usingthe paired t-test which previously was preceded by the normality test.

Results: The majority of respondents were having a higher educational level $(95.2 \%)$, working $(57.1 \%)$, and pregnant $(66.7 \%)$. In the pre-test, the number of respondents who had been well-educated was 5 people (23.81\%). Meanwhile, in the post-test, the number of respondents who were well-educated was 16 people (76.2\%). Moreover, the significance value (2-tailed) was 0.004 ( $p<0.05)$.

Conclusion: Online health education through WhatsApp can increase knowledge regarding breastfeeding preparation.

Keywords: Health Education, Breastfeeding Preparation, Childbearing-Age Women

\section{PENDAHULUAN}

ASI merupakan makanan pertama, utama dan terbaik bagi bayi sampai bayi berumur 6 bulan. ASI diberikan sedini mungkin setelah persalinan dan tanpa dijadwal (Prasetyono, 2009). Memberikan ASI untuk bayi menjadi tantangan untuk ibu walaupun menyusui merupakan suatu hal yang alamiah. Keberhasilan dalam menyusui tetap memerlukan pengetahuan tentang ASI dan tatalaksananya (Roesli, 2009).

Proses menyusui tidak selalu berjalan baik karena menyusui bukan sesuatu yang terjadi dengan sendirinya, tetapi merupakan suatu keterampilan yang perlu diajarkan dan dipersiapkan sejak hamil (Yuliarti, 2010). Ibu sering kurang mengetahui dan memahami tata laksana menyusui yang benar, seperti pentingnya memberikan ASI, bagaimana ASI keluar, bagaimana posisi menyusui dan perlekatan yang baik. Serta bagaimana cara ibu memberikan ASI bila terpisah dengan bayinya (Astutik, 2014).

Persiapan menyusui penting, karena mempersiapkan ibu secara fisik maupun secara psikologis. Persiapan yang perlu dilakukan ibu agar berhasil menyusui yaitu persiapan fisik berupa makanan yang bergisi, senam hamil, pemeriksaan kehamilan dan istirahat yang cukup. Kemudian persiapan mental dengan meyakinkan ibu bahwa menyusui merupakan proses alamiah, menambah pengetahuan ibu tentang ASI dan mengikutsertakan suami dan anggota keluarga lain untuk mendukung ibu dalam menyusui (Yuliarti, 2010).

Pengetahuan sangat penting sebab dari pengalaman dan penelitian terbukti bahwa perilaku yang didasari pengetahuan akan lebih langsung diterima daripada perilaku yang tidak didasari oleh pengetahuan (Notoadmojo, 2010). Pengetahuan yang benar tentang menyusui, kelengkapan alat untuk memompa ASI dan dukungan ligkungan kerja, seorang ibu yang bekerja dapat memberikan ASI secara eksklusif. 
Peningkatan pengetahuan ibu dalam pemberian ASI dapat dilakukan dengan pendidikan kesehatan. Banyaknya informasi menambah pengetahuan dan keterampilan seseorang, menimbulkan kesadaran dan akhirnya akan mengubah perilaku seseorang sesuai pengetahuannya (Notoatmodjo, 2010). Edukasi menyusui sangat penting untuk memulai proses menyusui dan dukungan dari pelayanan kesehatan seperti dukungan tenaga kesehatan sangat penting untuk membantu mempertahankan pemberian ASI (Jang, 2010).

Berdasarkan fenomena tersebut, peneliti tertarik untuk meneliti mengenai pengaruh pendidikan kesehatan terhadap pengetahuan persiapan menyusui pada Wanita Usia Subur (WUS).

\section{METODE PENELITIAN}

Desain yang digunakan dalam penelitian ini adalah rancangan penelitian Quasi Eksperiment dengan menggunakan rancangan pre post untuk membandingkan tindakan yang dilakukan sebelum dan sesudah diberikan perlakuan dan menggunakan jenis rancangan one group design. Variabel bebas dalam penelitian ini adalah pendidikan kesehatan persiapan menyusui sedangkan variabel terikatnya adalah pengetahuan wanita usia subur.

Sampel penelitian yang digunakan dalam penelitian ini sebanyak 21 responden dari 38 responden yang mengikuti kegiatan pendidikan kesehatan. Pendidikan kesehatan mengenai persiapan menyusui dilakukan secara online via WhatsApp. Resonden dimasukkan ke dalam grup WhatsApp, lalu mengerjakan pre test, setelah itu diberikan materi mengenai persiapan menyusui dalam bentuk pdf. Responden diberikan waktu 2 hari untuk mempelajari materi tersebut dan mengajukan pertanyaan. Sesuai waktu yang ditentukkan kemudian pertanyaanpertanyaan yang masuk dijawab. Setiap pertanyaan yang dijawab narasumber kemudian ditanggapi oleh responden dan responden dapat bertanya kembali ketika dirasa jawaban belum dimengerti. Kemudian setelah diskusi online ditutup, peneliti melakukan post test kepada responden.

Analisis data dilakukan secara kuantitatif menggunakan analisis univariat untuk menganalisis secara deskriptif variabel penelitian dengan menyajikan data dalam bentuk tabel distribusi frekuensi dan narasi sebagai penjelasan dari tabel yang disajikan dan analisis bivariat untuk mengetahui pengaruh pendidikan kesehatan terhadap pengetahuan persiapan menyusui pada Wanita Usia Subur (WUS) dengan menggunakan analisis Paired T Test yang sebelumnya telah dilakukan uji normalitas. 


\section{HASIL DAN PEMBAHASAN}

\section{Hasil}

Tabel 1 Distribusi Frekuensi Karakteristik Responden Berdasarkan Pendidikan, Pekerjaan dan Status Kehamilan

\begin{tabular}{lcc}
\hline \multicolumn{1}{c}{ Karakteristik Responden } & Frekuensi & Persentase (\%) \\
\hline Tingkat Pendidikan & 1 & 4,8 \\
Menengah & 20 & 95,2 \\
Tinggi & 21 & 100 \\
Total & & \\
Pekerjaan & 9 & 42,9 \\
Tidak Bekerja & 12 & 57,1 \\
Bekerja & 21 & 100 \\
Total & & \\
Kehamilan & 7 & 33,3 \\
Tidak Hamil & 12 & 66,7 \\
Hamil & 21 & 100 \\
Total & & \\
\hline
\end{tabular}

Dari data diatas menunjukkan bahwa mayoritas responden berada pada tingkat pendidikan tinggi yaitu sebanyak 95,2\% (20 orang). Responden yang bekerja lebih banyak dibandingkan yang tidak bekerja (ibu rumah tangga) yaitu $57,1 \%$ (12 orang). Kemudian untuk responden mayoritas dalam keadaan hamil yaitu sebanyak $66,7 \%$ (12 orang).

Masyarakat yang berpendidikan mampu memandang jah ke depan. Pendidikan mampu meningkatkan kemampuan seseorang pada ranah kognitif, afektif dan psikomotor. Ranah kognitif mampu meningkatkan pengetahuan, ranah afektif dapat menentukkan sikap, membentuk pola hidup sedangkan ranah psikomotor dapat mempersepsi diri, membuat penyesuaian pola gerak (Suwarno, Sartohadi, Sunarto \& Sudharta, 2014).

Pekerjaan merupakan salah satu faktor yang mempengaruhi pengetahuan. Seseorang yang bekerja akan sering berinteraksi dengan orang banyak sehingga memiliki pengetahuan yang baik pula (Anoraga, 2014). Konseling menyusui bagi ibu bekerja diperlukan agar ibu bekerja mempunyai kesabaran dan ketekunan dalam memerah dan memberikan ASI perah kepada bayi saat ditinggal bekerja (Iellamo, 2015). Tantangan bagi ibu yang bekerja untuk melanjutkan menyusui adalah kurangnya fasilitas menyusui dan kurangnya istirahat saat bekerja, sehingga sulit untuk melakukan pekerjaan dan kewajiban menyusui secara bersamaan. 
Tabel 2 Perbedaan Sebelum dan Sesudah Diberikan Pendidikan Kesehatan Berdasarkan Karakteristik Responden

\begin{tabular}{lcccccc}
\hline \multicolumn{1}{c}{ Karakteristik } & \multicolumn{3}{c}{ Pre Test } & \multicolumn{3}{c}{ Post Test } \\
\cline { 2 - 6 } \multicolumn{1}{c}{ Responden } & Baik & Cukup & Kurang & Baik & Cukup & Kurang \\
\hline Pendidikan & 0 & 1 & 0 & 1 & 0 & 0 \\
Menengah & $(0 \%)$ & $(4,76 \%)$ & $(0 \%)$ & $(4,76 \%)$ & $(0 \%)$ & $(0 \%)$ \\
Tinggi & 5 & 9 & 6 & 15 & 3 & 2 \\
Pekerjaan & $(23,81 \%)$ & $(42,86 \%)$ & $(28,57 \%)$ & $(71,43 \%)$ & $(14,28 \%)$ & $(9,52 \%)$ \\
Tidak Berkerja & 0 & & & & 1 & 1 \\
Bekerja & $(0 \%)$ & $(28,57 \%)$ & $(14,28 \%)$ & $(33,33 \%)$ & $(4,76 \%)$ & $(4,76 \%)$ \\
Status Kehamilan & 5 & 4 & 3 & 9 & 2 & 1 \\
Tidak hamil & $(23,81 \%)$ & $(19,05 \%)$ & $(14,28 \%)$ & $(42,86 \%)$ & $(9,52 \%)$ & $(4,76 \%)$ \\
& 2 & & & & \\
Hamil & $(9,52 \%)$ & $(14,28 \%)$ & $(9,52 \%)$ & $(19,05 \%)$ & $(9,52 \%)$ & $(4,76 \%)$ \\
& 3 & 7 & 4 & 12 & 1 & 1 \\
& $(14,28 \%)$ & $(33,33 \%)$ & $(19,05 \%)$ & $(57,14 \%)$ & $(4,76 \%)$ & $(4,76 \%)$ \\
\hline
\end{tabular}

Berdasarkan tabel diatas sebelum diberikan pendidikan kesehatan, responden yang berpendidikan tinggi hasil pre testnya mayoritas dalam kategori cukup 42,86\% (9 orang), kemudian setelah diberikan pendidikan kesehatan, responden yang berpendidikan tinggi mayoritas dalam kategori baik yaitu $71,43 \%$ (15 orang). Tinggi rendahnya pendidikan seseorang menentukan pengetahuan, sikap dan perilaku (Sriyono, 2015).

Responden yang bekerja sebelum diberikan pendidikan kesehatan mayoritas dalam kategori baik 23,81\% (5 orang) dan setelah diberikan pendidikan kesehatan kategori baik bertambah menjadi 42,86\% (9 orang). Seseorang yang bekerja di luar rumah cenderung memiliki akses yang baik terhadap informasi.

Sebelum diberikan pendidikan kesehatan mayoritas responden yang hamil dalam kategori cukup yaitu 33,33\% (7 orang) dan setelah diberikan pendidikan kesehatan mayoritas responden yang hamil dalam kategori baik 57,14\% (12 orang). Manajemen laktasi harus dilakukan pada masa prenatal secara formal dan harus menjadi komponen rutin perawatan antenatal untuk semua ibu hamil.

Breastfeeding education pada masa prenatal dengan usia kehamilan 20-36 minggu, efektif untuk meningkatkan pengetahuan, sikap dan kepuasan mereka dalam menyusui berdasarkan penelitian yang dilakukan oleh Lin, Chien, Tai \& Lee (2008). Pada trimester ketiga seorang ibu harus dilatih atau diajarkan tentang bagaimana cara menyusui bayi menggunakan alat peraga seperti boneka, bola dan balon (Wood, Hineman \& Meyers, 2009). 
Tabel 3 Tabulasi Silang Sebelum dan Sesudah Diberikan Pendidikan Kesehatan Mengenai Persiapan Menyusui dan Analisis Bivariat

\begin{tabular}{lccccc}
\hline \multirow{2}{*}{$\begin{array}{c}\text { Pre Test } \\
\text { Persiapan } \\
\text { Menyusui }\end{array}$} & Baik & Cukup & Kurang & Total & Sig \\
\cline { 2 - 4 } Baik & 4 & 0 & 1 & & \\
Cukup & $(19,05 \%)$ & $(0 \%)$ & $(4,76 \%)$ & $(23,81 \%)$ & \\
& 8 & 1 & 1 & 10 & \\
Kurang & $(38,1)$ & $(4,76 \%)$ & $(4,76 \%)$ & $(47,62 \%)$ & 0,004 \\
\multirow{2}{*}{ Total } & 4 & 2 & 0 & 6 & \\
& $(19,05 \%)$ & $(9,52 \%)$ & $(0 \%)$ & $(28,57 \%)$ & \\
\hline
\end{tabular}

Pada saat pre test jumlah responden yang berpengetahuan baik sebanyak 5 orang $(23,81 \%)$ dan responden yang berpengetahuan kurang sebanyak 6 orang $(28,57 \%)$. Kemudian pada saat post test jumlah responden yang berpengetahuan baik sebanyak 16 orang $(76,2 \%)$ dan jumlah responden yang berpengetahuan kurang sebanyak 2 orang $(9,52 \%)$.

Nilai signifikansi (2-tailed) adalah $0,004(\mathrm{p}<0,05)$ sehingga hasil pre test dan post test mengalami perubahan yang signifikan (berarti). Disimpulkan pendidikan kesehatan online melalui aplikasi whatsapp dapat meningkatkan pengetahuan tentang persiapan menyusui.

\section{Pembahasan}

Berdasarkan hasil penelitian ini, pengetahuan tentang persiapan menyusui yang paling banyak tidak diketahui responden adalah tentang kandungan kolostrum serta manfaat menyusui yang dapat menunda kesuburan. Sedangkan pengetahuan yang paling banyak diketahui oleh responden adalah mengenai perawatan payudara dimana tidak menggunakan bra berkawat dan tidak menggunakan sabun untuk membersihkan payudara.

Air Susu Ibu (ASI) adalah nutrisi yang ideal bagi bayi dan berkontribusi bagi pertumbuhannya. ASI adalah makanan pertama dan pilihan terbaik bagi bayi pada awal kehidupannya (Riordan, 2010). Laktasi adalah keseluruhan proses menyusui mulai dari ASI diproduksi sampai proses bayi menghisap dan menelas ASI. Laktasi merupakan bagian integral dari siklus reproduksi manusia (Ambarwati, 2010). Menyusui merupakan proses alamiah, namun sering ibu tidak berhasil menyusui atau menghentikan menyusui lebih dini. Sehingga ibu memerlukan bantuan agar proses menyusui berhasil. Pendidikan kesehatan dilaksanakan dengan memperhatikan beberapa hal agar pendidikan kesehatan berhasil seperti kesesuaian sasaran dan waktu yang tetap, lingkungan, alat bantu dan materi yang disampaikan (Efendi \& Makhfudli, 2009).

Penelitian ini sesuai dengan penelitian yang dilakukan oleh Himawati \& Mawarti (2011) bahwa terdapat perbedaan antara sebelum dan sesudah dilakukan 
intervensi pendidikan kesehatan. Penelitian yang dilakukan oleh Astria (2012) menunjukkan bahwa pendidikan kesehatan yang diberikan dapat meningkatkan pengetahuan ibu menyusui. Salah satu upaya pemenuhan target dalam pemberian ASI eksklusif dengan memberikan pendidikan kesehatan manajemen laktasi pada ibu primipara. Sejalan dengan penelitian yang dilakukan oleh Roihatul (2014) dimana pendidikan kesehtan yang diberikan meningkatkan motivasi Ibu primipara dalam memberikan ASI.

Berdasarkan hasil penelitian yang dilakukan oleh Atabik (2013) menyarankan bahwa ibu sebaiknya lebih aktif mencari informasi tentang pentingnya memberi ASI eksklusif, guna meningkatkan pengetahuan agar dapat menyusui anak secara eksklusif. Hasil penelitian Sriningsih (2011) bahawa penyuluhan manajemen laktasi yang diberikan kepada ibu-ibu saat antenatal, intranatal dan prenatal untuk keberhasilan menyusui secara eksklusif.

Edukasi saat antenatal lebih penting daripada setelah persalinan karena pengaruh seperti iklan susu formula sangat berpengaruh dalam menggagalkan pemberian ASI terutama pada ibu yang berpendidikan rendah (Fikawati, 2009).

\section{SIMPULAN DAN SARAN}

\section{Simpulan}

Berdasarkan analisis data dan hasil pembahasan yang dijelaskan sebelumnya, maka dapat diambil kesimpulan bahwa terdapat pengaruh pendidikan kesehatan persiapan menyusui terhadap pengetahuan tentang persiapan menyusui pada Wanita Usia Subur (WUS).

\section{Saran}

Berdasarkan kesimpulan yang dikemukakan di atas, saran yang dapat dikemukakan adalah pendidikan kesehatan tentang persiapan menyusui diperlukan oleh wanita usia subur dimana untuk menambah pengetahuannya, sehingga ketika wanita tersebut hamil, bersalin dan menyusui, proses menyusui sudah lebih siap secara fisik maupun mental. Pendidikan kesehatan dapat dilakukan secara online karena terbukti efektif.

\section{DAFTAR PUSTAKA}

Ambarwati, Wulandari. 2010. Asuhan Kebidanan Nifas. Yogyakarta : Nuha Medika.

Anoraga, P. 2014. Psikologi Kerja. Jakarta : Rineka Cipta.

Astria, I. 2012. Pengaruh Pendidikan Kesehatan Teknik Menyusui terhadap Pengetahuan Ibu Primipara di RSIA Siti Fatimah Makassar. Skripsi. Dipublikasikan. ISSN 2302-2531 Volume 1 No. 1 Tahun 2012.

Astutik. 2014. Manajemen Laktasi. Jakarta : Salemba Medika. 
Atabik, A. 2012. Faktor Ibu yang Berhubungan dengan Praktik Pemberian ASI Eksklusif di Wilayan Kerja Puskesmas Pamotan. Unnes Journal of Public Health, 1(1):1-9.

Efendi, F., \& Makhfudli. 2009. Keperawatan Kesehatan Komunitas : Teori dan Praktik dalam Keperawatan. Jakarta : Salemba Medika.

Fikawati, S., \& Syafiq, A. 2009. Penyebab Keberhasilan dan Kegagalan Praktik Pemberian ASI Eksklusif. Jurnal Kesehatan Masyarakat Nasional, 4(3):120131.

Himawati, L., \& Mawarti, R. 2011. Pengaruh Pendidikan Kesehatan tentang Teknik Menyusui terhadap Pengetahuan dan Perilaku Teknik Menyusui pada Ibu Primipara di BPS Kecamatan Kalibawang Kulonprogo Tahun 2011. STIKES 'Aisyiyah Yogyakarta.

Iellamo, A., Sobel, H., \& Engelhardt, K. 2015. Working Mothers of the World Health Organization Western Pacific Offices: Lessons and Experiences to Protect, Promote and Support Breastfeeding. Journal of Human Lactation, 31(1):36-39.

Jang, G., \& Kim, S. 2010. Effects of Breastfeeding Education and Support Services on Breastfeeding Rates and Infant's Growth. Journal of Korean Academy of Nursing, 40(2):277-286.

Lin, S.S., Chien, L. Y., Tai, C. J., \& Lee, C. F. 2008. Effectiveness of a prenatal education programme on breastfeeding outcomes in Taiwan. Journal of Clinical Nursing, 1.

Notoatmodjo, S. 2010. Ilmu Perilaku Kesehatan. Jakarta : Rineka Cipta.

Prasetyono, S.D. 2009. ASI Eksklusif. Yogyakarta : Diva Press.

Riordan, J \& Wambach, K. 2010. Breastfeeding and Human Lactation Fourth Edition. Sudbury : Jones and Bartlett Publisher.

Roesli, Utami. 2009. Panduan Praktis Menyusui. Jakarta: Pustakan Bunda.

Roihatul Zahroh, M.I.L. 2014. Pendidikan Kesehatan Meningkatkan Motivasi Ibu Primipara dalam Memberikan ASI, 5(1), 56-62.

Sriningsih, I. 2013. Faktor Demografi, Pengetahuan Ibu tentang Air Susu Ibu dan Pemberian ASI Eksklusif. Jurnal Kesmas, 8(2):113-120.

Sriyono. 2015. Pengaruh Tingkat Pendidikan dan Pemahaman Masyarakat tentang Ikan Berformalin terhadap Kesehatan Masyarakat, Faktor Exacta, $8(1), 79-91$.

Suwarno., Sartohadi, J., Sunarto \& Sudharta, D. 2014. Kajian Pengaruh Tingkat Pendidikan terhadap Perilaku Masyarakat dalam Pengelolaan Lahan Rawan Longsor Lahan di Kecamatan Pekuncen Kabupaten Banyumas. Geoedukasi, III (1), 15-22.

Wood, J., Hineman, E., \& Meyers, D. 2009. Clinical Protocol Number \#19: Breastfeeding Promotion in the Prenatal Setting. Breastfeeding Medicine, 44.

Yuliarti, N. 2020. Keajaiban ASI - Makanan Terbaik Untuk Kesehatan, Kecerdasan dan Kelincahan Si Kecil. Yogyakarta : CV Andi Offset. 